\title{
Trends in asbestos body counts in bronchoalveolar lavage fluid over two decades
}

\author{
P. Dumortier*, J. Thimpont*,\#, V. de Maertelaer", P. De Vuyst*
}

Trends in asbestos body counts in bronchoalveolar lavage fluid over two decades. P. Dumortier, J. Thimpont, V. de Maertelaer, P. De Vuyst. (C)ER Journals Ltd 2003. ABSTRACT: As in most western countries, the use of asbestos has decreased in Belgium since the mid 1970's. Successive regulations have lowered the permissible levels of exposure and prohibited the use of various asbestos products.

In order to assess the impact of these prevention measures on the pulmonary fibre burden of asbestos-exposed patients, the bronchoalveolar lavage fluid (BALF) asbestos body (AB) analysis database of the authors' laboratory was reviewed for the period 1983-2000.

A total of 4,772 cases were considered, of which $95 \%$ were males. AB concentration exceeded $1 \mathrm{AB} \cdot \mathrm{mL} \mathrm{BALF}^{-1}$ in $36.1 \%$. There was essentially no change in the mean concentration of $\mathrm{AB}$ over the period evaluated. However, the concentrations in individuals with very high levels decreased over time. This was associated with a shift in exposure categories from primary asbestos workers to those exposed during handling of asbestos-containing materials or to asbestos in place in buildings or industrial sites.

This is consistent with epidemiological data indicating that the number of severe cases of asbestosis caused by very high cumulated doses decreases but that benign pleural diseases and mesothelioma remain the most frequent asbestos-related diseases. Past prevention measures are not expected to have a measurable influence on the incidence of mesothelioma in the near future.

Eur Respir J 2003; 22: 519-524.
*Chest Dept, Hôpital Erasme, ${ }^{*}$ Occupational Diseases Fund, and Biostatistics, Institut de Recherche Interdisciplinaire en Biologie Humaine et Moléculaire, Faculty of Medicine, Université Libre de Bruxelles, Brussels, Belgium.

Correspondence: P. Dumortier

Chest Dept

Cliniques Universitaires de Bruxelles

Hôpital Erasme

Route de Lennik 808

B1070 Brussels

Belgium

Fax: 3225554411

E-mail: pdumorti@ulb.ac.be

Keywords: Asbestos body

bronchoalveolar lavage

mesothelioma

trend

Received: January 82003

Accepted after revision: May 142003
Restrictive regulations for occupational asbestos exposure levels and prohibitions concerning the use of certain types of products were gradually implemented in parallel with the accumulation of evidence about the adverse effects of asbestos on health. The utilisation of asbestos has declined since the mid 1970's and its use is now banned or strictly controlled in many Western countries $[1,2]$.

In Belgium, a total of $\sim 2 \times 10^{6}$ tons of asbestos has been imported since 1948. It can be deduced from the geographical origin of imported asbestos that amphiboles accounted for $5-10 \%$ of the Belgian imports. In 1978, asbestos spraying, asbestos insulation and raw asbestos handling were banned. The threshold limit values (TLV)s for occupational asbestos exposures were set at $0.2 \mathrm{f} \cdot \mathrm{mL}^{-1}$ for crocidolite and to $2 \mathrm{f} \cdot \mathrm{mL}^{-1}$ for all other types of asbestos. In 1986, these values were reduced to 0.15 and $1 \mathrm{f} \cdot \mathrm{mL}^{-1}$, respectively. In 1991 , the TLVs were set to $0.15 \mathrm{f} \cdot \mathrm{mL}^{-1}$ for all amphiboles and $0.5 \mathrm{f} \cdot \mathrm{mL}^{-1}$ for chrysotile. The use of asbestos was banned in 1998, except for a few specific applications allowed until 1st January 2002.

Exposure to asbestos-containing materials (ACM)s in buildings or in industrial sites is still a concern for many trades. Progressive degradation due to aging of these materials or to maintenance work may release airborne fibres and constitute a potential hazard for several occupational groups, such as construction and maintenance workers, electricians, and steel or refinery workers [1, 3-6].

Counting asbestos bodies (AB)s in bronchoalveolar lavage fluid (BALF) by light microscopy can be used to help evaluate an individual's past exposure to asbestos [7]. ABs mainly reflect exposure to amphibole asbestos. Concentrations $>1$
$\mathrm{AB} \cdot \mathrm{mL} \mathrm{BALF}^{-1}$ usually indicate an asbestos exposure exceeding that of the general population [8].

BALF samples have been sent to the current authors' laboratory by chest physicians throughout Belgium since 1980 and a systematic database has been maintained since 1983 . The aim of this study was to analyse whether past reductions in the use of asbestos and in exposure levels in Belgium would be reflected as changes in the BALF AB counts over the period 1983-2000.

\section{Materials and methods}

Samples analysed between 1 January 1983 and 31 December 2000 were identified from the database. The following exclusions were made: 1) where several samples are available for the same patient, only the result of the first suitable sample was included; 2) samples from Turkish immigrants with possible environmental exposures to tremolite or erionite in Turkey [9] were excluded; 3) samples with $<5 \mathrm{~mL}$ of BALF $(\mathrm{n}=40)$ were excluded because such a small volume is probably associated with sampling problems; and 4) all cases where sampling problems were mentioned were excluded. Information on sex and age were available for most patients, but details concerning BALF quality, cells counts, occupational exposure and disease were often incomplete or missing. For the subgroup of patients with counts above the annual 95th percentile, additional information about occupation and disease was collected from the files of the Belgian Occupational Diseases Fund. 
Table 1. - Number of cases examined between 1983-2000, mean age, sex ratio and percentages of samples without asbestos bodies $(A B) s$ and with $A B$ counts $>1$ and $5 A B \cdot \mathrm{mL}^{-1}$ bronchoalveolar lavage fluid (BALF) thresholds

\begin{tabular}{|c|c|c|c|c|c|c|}
\hline Period & Cases n & Age yrs & Sex ratio $\mathrm{M} / \mathrm{F}$ & No ABs in BALF $\%$ & $\geqslant 1 \mathrm{AB} \cdot \mathrm{mL} \mathrm{BALF}{ }^{-1} \%$ & $\geqslant 5 \mathrm{AB} \cdot \mathrm{mL} \mathrm{BALF}{ }^{-1} \%$ \\
\hline 1983-1985 & 748 & $54.7 \pm 12.4$ & 17.6 & 38.6 & 39.3 & 21.1 \\
\hline 1986-1988 & 777 & $56.4 \pm 12.5$ & 12.4 & 34.2 & 34.1 & 17.6 \\
\hline 1989-1991 & 812 & $58.0 \pm 12.7$ & 19.8 & 35.1 & 39.2 & 16.7 \\
\hline 1992-1994 & 800 & $59.5 \pm 11.6$ & 16.8 & 34.3 & 37.3 & 19.2 \\
\hline 1995-1997 & 858 & $59.4 \pm 12.4$ & 22.8 & 36.2 & 31.8 & 15.2 \\
\hline 1998-2000 & 777 & $60.6 \pm 12.3$ & 16.7 & 34.1 & 35.4 & 17.1 \\
\hline All & 4772 & $58.3 \pm 12.4$ & 17.2 & 35.4 & 36.1 & 17.8 \\
\hline
\end{tabular}

Data are presented as $\mathrm{n}$ or $\%$ as indicated or mean $\pm \mathrm{SD}$. M: male; F: female.

The study period was divided into two equal subperiods to examine possible shifts in the proportions of positive cases among the whole population and of occupations or diseases among those with counts above the annual 95th percentiles.

Assuming that the majority of the cases had started their main occupation around the age of $20 \mathrm{yrs}$, the date of entrance into working life was estimated according to the following algorithm:

$$
\begin{aligned}
& \text { date of entrance into working life }= \\
& \text { date of BALF sampling }- \text { age }+20
\end{aligned}
$$

$\mathrm{Na}$ hypochlorite digestion and filtration on membrane filters (Millipore Corporation, Bedford, MA, USA) were used to collect the ABs from BALF. Counting was performed by phase contrast light microscopy [8]. The analytical sensitivity was $\sim 0.1 \mathrm{AB} \cdot \mathrm{mL} \mathrm{BALF}^{-1}$. The mean volume of BALF analysed was $26 \pm 15 \mathrm{~mL}$ (range 5-195). An analytical transmission electron microscope fitted with an energy dispersive $\mathrm{x}$-ray analyser was used to determine the nature of the core fibre of ABs in some cases.

\section{Statistical analysis}

Ages and durations of exposure were compared using the unpaired t-test. The Chi-squared test was used to look for a possible relationship between categories of age, AB threshold, or occupation and the sampling period. Mean concentrations are reported as geometric mean (GM), geometric standard deviation and $95 \%$ confidence interval of the GM. Linear regression analysis was used to assess the trend of $\mathrm{AB}$ concentrations over time. A value of half the analytical sensitivity of the method $\left(0.05 \mathrm{AB} \cdot \mathrm{m}^{-1}\right)$ was attributed to null counts in order to enable graphical presentation of concentrations on a logarithmic scale and calculation of regression lines.

\section{Results}

There were 4,772 eligible samples between 1983-2000. Annual numbers of samples ranged 220-329. The mean age of the patients was 58 yrs (range 17-92) and 95\% of the patients were male. There was no marked change in the sex ratio between 1983-2000, while the mean age of the patients increased by 6 yrs over the study period (table 1 ). AB concentrations ranged from $<0.1$ to $4,661 \mathrm{AB} \cdot \mathrm{mL}^{-1}$. They exceeded $1 \mathrm{AB} \cdot \mathrm{mL}^{-1}$ in $1,723(36.1 \%)$ samples and $5 \mathrm{AB} \cdot \mathrm{mL}^{-1}$ in 848 $(17.8 \%)$. There were no ABs in $1,689(35.4 \%)$ of the BALF samples. The fraction of samples without ABs did not change over the study period (table 1). They accounted for 34\% of the samples in males and $57 \%$ in females.

The proportion of samples with $\geqslant 1 \mathrm{AB} \cdot \mathrm{mL}^{-1}$ decreased significantly from 1983-1991 to 1992-2000 among those aged $<50$ yrs, but did not change among those aged $>50$ yrs (table 2).

Figure 1 shows a very small, but significant, decrease of the mean concentrations over years, with a linear regression analysis equation as follows:

$$
\log [\mathrm{AB}]=16.542-0.00846 \times \text { year }
$$

(pslope and pintercept $<0.005, \mathrm{R}^{2}=0.0016$ ). However, this trend becomes nonsignificant if the 36 patients with the highest counts are excluded. The lowest count in this subgroup was $390 \mathrm{AB} \cdot \mathrm{mL}^{-1}$.

A linear regression model was also used to assess the trend for the patients with concentrations above the respective annual 95th percentiles $(n=246)$, as a further quadratic term was not statistically significant $(\mathrm{p}=0.079)$. The linear regression equation was as follows:

$$
\log [\mathrm{AB}]=93.526-0.046 \times \text { year }
$$

\begin{tabular}{|c|c|c|c|c|c|}
\hline & \multicolumn{2}{|c|}{ 1983-1991 } & \multicolumn{2}{|c|}{$1992-2000$} & \multirow[t]{2}{*}{ Chi-squared } \\
\hline & $<1 \mathrm{AB} \cdot \mathrm{mL}^{-1}$ & $\geqslant 1 \mathrm{AB} \cdot \mathrm{mL}^{-1}$ & $<1 \mathrm{AB} \cdot \mathrm{mL}^{-1}$ & $\geqslant 1 \mathrm{AB} \cdot \mathrm{mL}^{-1}$ & \\
\hline Cases $n$ & \multicolumn{2}{|c|}{2337} & \multicolumn{2}{|c|}{2435} & \\
\hline Age & & & & & \\
\hline Unknown & $285(63)$ & $167(37)$ & $116(67)$ & $57(33)$ & $\mathrm{p}=0.350$ \\
\hline$\leqslant 50$ yrs & 344 (64) & $195(36)$ & $350(72)$ & 139 (28) & $\mathrm{p}=0.008$ \\
\hline$>50 \mathrm{yrs}$ & $832(62)$ & $514(38)$ & $1123(63)$ & $650(37)$ & $\mathrm{p}=0.383$ \\
\hline
\end{tabular}

(pslope and pintercept $<0.001$ ) (fig. 2). The type and duration of

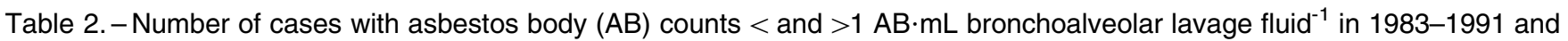
1992-2000 according to age

Data are presented as $\mathrm{n}(\%)$ unless otherwise stated. 


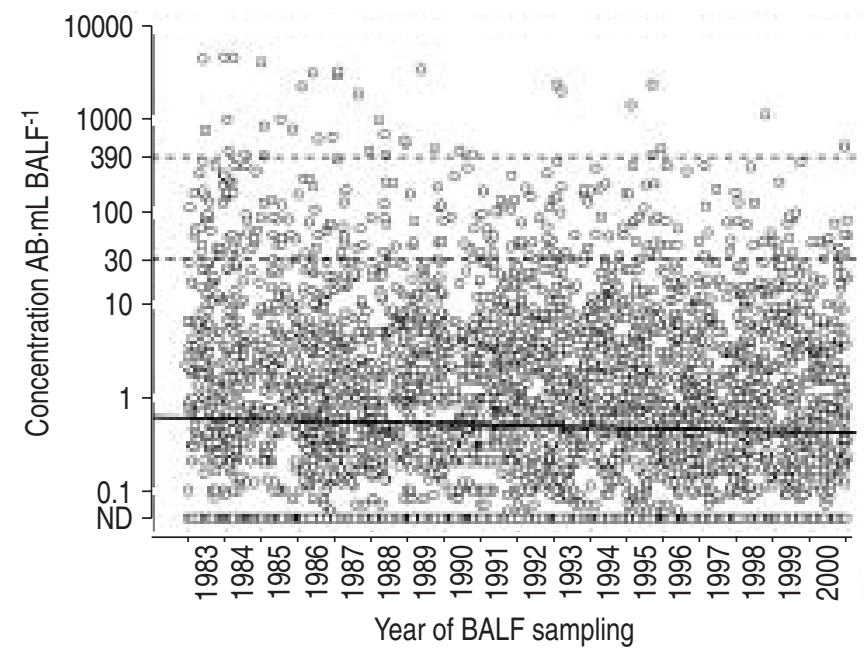

Fig. 1. - Scatterplot of asbestos body (AB) concentrations in bronchoalveolar lavage fluid (BALF) according to the year of sampling. The equation of the regression line is $\log [\mathrm{AB}]=16.542-0.00846 \times$ year $(-)$. Levels of 390 and $30 \mathrm{AB} \cdot \mathrm{mL} \mathrm{BALF}^{-1}$ are also indicated (----) (see Results and Discussion sections). ND: not detected.

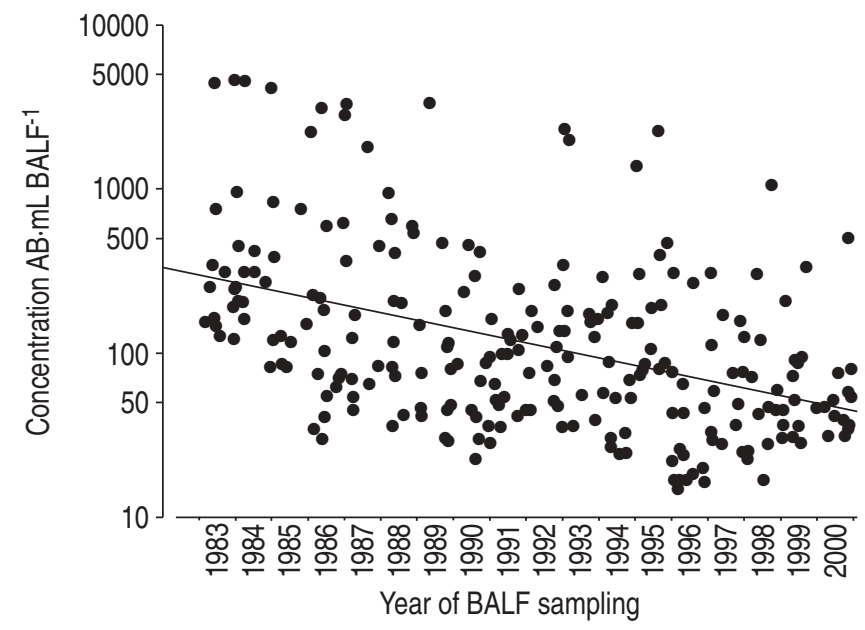

Fig. 2. - Detailed scatterplot of asbestos body (AB) concentrations in bronchoalveolar lavage fluid (BALF) exceeding the annual 95th percentile according to the year of sampling. The equation of the regression line is $\log [\mathrm{AB}]=93.526-0.046 \times$ year $(-)$.

occupational exposure were known for 222 (90\%) and 202 $(82 \%)$, respectively, of these 246 patients (table 3 ). Time elapsed since end of exposure was rarely available. Patients sampled in 1983-1991 were slightly younger than those sampled in 1992-2000 ((mean $\pm \mathrm{SD}) 57 \pm 11$ versus $61 \pm 11 \mathrm{yrs}$; $\mathrm{p}=0.0016)$ but the duration of exposure did not differ $(21 \pm 10$ versus $23 \pm 12$ yrs; $\mathrm{p}=0.17)$. Occupations were categorised into three groups according to the type of asbestos exposure as follows: 1) group I: those engaged in handling of raw asbestos, in installation of asbestos insulation or in production of ACMs; 2) group II: those whose occupational titles suggest contact to asbestos in place or use of ACMs; and 3) group III: the remaining occupations with either rare or less homogeneous asbestos exposure. Details about the types of occupations included in each of the groups are given in the footnote of table 3. Figure 3 shows that the proportion of patients in group I was significantly higher in 1983-1991 than in 1992-2000, while the proportion of patients in group II was higher in 1992-2000 $(\mathrm{p}<0.0001)$. The Occupational Disease Fund had files for 170 of the 246 patients $(69 \%)$ and 146 had
Table 3. - Distribution of type of exposure and disease among cases with asbestos body counts in bronchoalveolar lavage fluid above the annual 95th percentile in 1983-1991 and 1992-2000 in Belgium

1983-1991

1992-2000

Cases $n$

120

126

Type of exposure

Group I

Group II

Group III

No data

120

126

Disease

Asbestosis

Lung cancer

Benign pleural disease alone

Malignant mesothelioma

Other pneumoconiosis"

No lung or pleural disease

No data on lung or pleural disease

$\begin{array}{cc}67 & 36 \\ 27 & 72 \\ 9 & 11 \\ 17 & 7 \\ & \\ 4 & 8 \\ 9 & 7 \\ 41 & 45 \\ 17 & 15 \\ 7 & 3 \\ 8 & 6 \\ 34 & 42\end{array}$

Group I occupations: furnace mason, furnace builder, refractory worker, insulator, asbestos sprayer, pipe coverer, asbestos cement production worker, brake lining production worker, shipyard worker, asbestos felt production, asbestos rubber production, asbestos bags handling; group II occupations: heating mechanic, pipe fitter, boiler fitter, steel worker, rolling mill operator, sheet metal worker, welder, construction worker, demolition worker, electrician, plumber, joiner, elevator installer, power plant worker; group III occupations: other trades including coal miner, talc crusher, decorator, painter, brake maintenance, silver recovery, batteries factory worker, spark plug factory worker, machine tool maintenance, locomotive maintenance, tram maintenance, passive exposure in a bystander, childhood familial contact. \#: silicosis, talcosis, mixed dust pneumoconiosis.

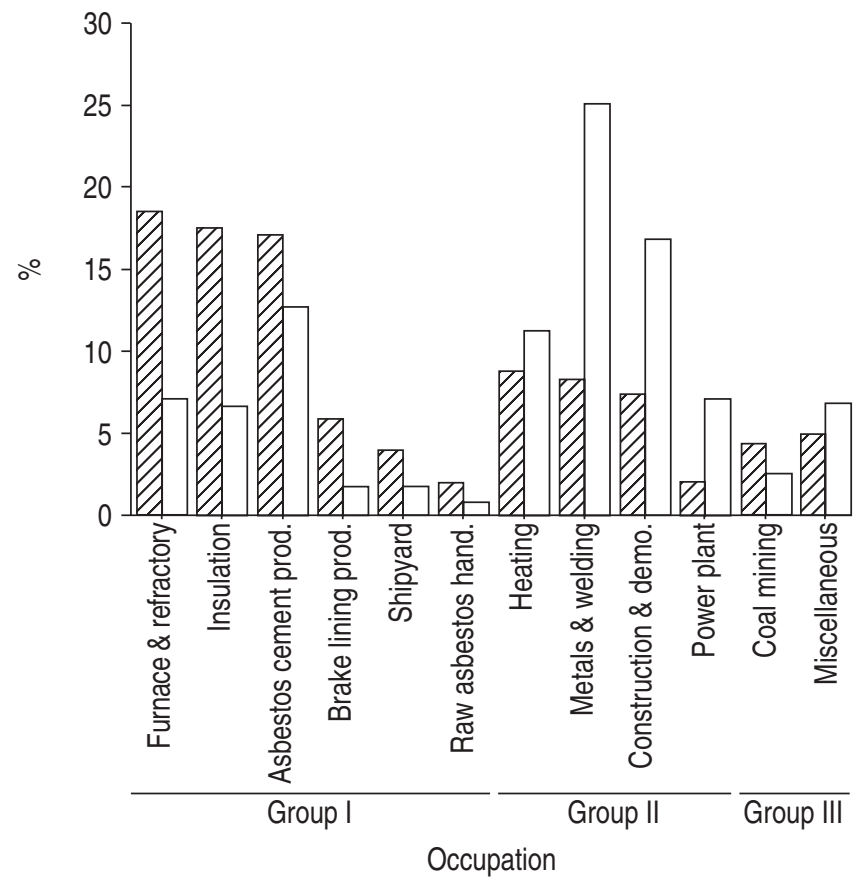

Fig. 3.-Distribution of occupations in the cases with asbestos body counts above the annual 95th percentile during the periods 1983-1991 $(\mathbb{Z} ; \mathrm{n}=103)$ and 1992-2000 $(\square ; \mathrm{n}=119)$ (see Results section and table 3 for definition of the groups). prod.: production; hand.: handling; demo.: demolition.

been recognised as having an asbestos-related disease. Seventy per cent of them had malignant mesothelioma or benign pleural diseases (table 3). Three patients with lung cancer during 1983-1991 also had asbestosis. All cases of asbestosis 
Table 4. - Distribution of bronchoalveolar lavage fluid (BALF) asbestos body $(\mathrm{AB})$ concentration according to year of entry into working life and age

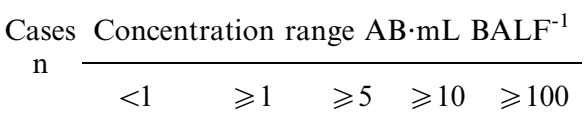

\begin{tabular}{|c|c|c|c|c|c|c|}
\hline \multicolumn{7}{|l|}{ Working life $<1978$} \\
\hline$>50 \mathrm{yrs}$ & 3119 & $62.7^{\#}$ & $37.3^{\#}$ & 18.1 & 11.6 & 2.3 \\
\hline$\leqslant 50$ yrs & 854 & 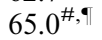 & 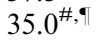 & 17.3 & 12.3 & 3.4 \\
\hline \multicolumn{7}{|l|}{ Working life $\geqslant 1978$} \\
\hline All $\leqslant 50$ yrs & 174 & $79.9^{\bullet}$ & $20.1^{\oplus}$ & 7.5 & 5.2 & 0.0 \\
\hline
\end{tabular}

Data are presented as \% unless otherwise stated. ${ }^{\#}$ : not significant $(\mathrm{p}=0.2154) ;{ }^{\uparrow}: \mathrm{p}<0.002$.

between 1983 and $1991(n=7)$ had been attributed a degree of disability $>40 \%$ compared to only one of eight between 1992 and 2000. This suggests that the more recent cases of lung fibrosis were less severe. Moreover, the diagnosis of asbestosis is essentially based on computed tomography scans since 1990, also contributing to the recognition of less severe cases. All the cases with asbestosis had $\mathrm{AB}$ counts $>100$ in 1983-1991, versus only three out of eight in 1992-2000.

All patients with counts $>1,000 \mathrm{AB} \cdot \mathrm{mL} \mathrm{BALF}^{-1} \quad(\mathrm{n}=15)$ entered working life before 1968, all those in the range 100-999 AB $\cdot \mathrm{mL}^{-1}(\mathrm{n}=105)$ before 1972 and all those in the range $50-99 \mathrm{AB} \cdot \mathrm{mL}^{-1}(\mathrm{n}=76)$ before 1980 . Table 4 shows that the proportion of cases with $>1 \mathrm{AB} \cdot \mathrm{mL}^{-1}$ is significantly lower among those who entered working life after 1978, the year when the first asbestos regulations were applied in Belgium. However, these cases were significantly younger than those in the same age range ( $<50$ yrs) who entered working life before 1978 (mean age 32.3 \pm 5.4 versus 43.5 $\pm 5.0 ; \mathrm{p}<0.001$ ). Nine cases $(5 \%)$ who had begun to work after 1978 had $>10 \mathrm{AB} \cdot \mathrm{mL} \mathrm{BALF}^{-1}$. Analytical transmission electron microscopy showed that the core fibre of the "typical" AB was only amosite or crocidolite in four cases, only chrysotile in three and mostly refractory ceramic fibres in two cases.

\section{Discussion}

The effect of the reduction of occupational exposure levels and asbestos consumption in Belgium since the mid 1970's on the pulmonary $\mathrm{AB}$ burden of the patients exposed to asbestos more than two decades later is very limited and some high exposures were still observed among the youngest age groups.

Most studies concerned with asbestos fibres or bodies in the human lungs have compared their concentrations with exposure characteristics and/or associated diseases in specific groups [10-15]. The changes in the use of asbestos have only been taken into account exceptionally in the interpretation of mineralogical findings [16]. Therefore, in this study, the evolution of a biomarker of asbestos exposure over a relevant period of time in a very large number of workers was examined.

Although the material is restricted to those individuals for whom a BAL was performed, i.e. individuals with some suspicion of an asbestos exposure or asbestos-related disease, the probability that any other selection process could have biased the results is low. For example, the samples were collected from referring chest departments with a wide geographical distribution all over Belgium, there was a wide variety of occupations and diseases, and the annual number of cases and the sex ratio were quite stable over the years. Furthermore, all the analyses had been made in the same laboratory with the same technique. In some instances, the BAL procedure may result in samples of poor quality [8], e.g. in cases with severe chronic obstructive pulmonary disease, but there is no evidence that the proportion of unsuitable samples has changed markedly over time. It is not possible to control whether clinicians become more confident in their diagnoses and send less samples of the more obvious cases, however, the statistics of the Occupational Diseases Fund confirm a decrease in the percentage of disability attributed to cases of asbestosis.

The main determinants of the $\mathrm{AB}$ burden in the lungs are related to exposure, to fibre type and individual factors. Intensity, duration and pattern of individual exposure may have varied widely over time, especially in jobs where preventive protection measures were implemented [17]. Type and size distribution of the fibres deposited in the lungs affect $\mathrm{AB}$ formation. ABs are mainly formed on amphibole asbestos fibres $>10 \mu \mathrm{m}$ in length $[18,19]$, whose clearance from the lung is low. They can be detected in BALF even $>40$ yrs after the end of exposure [20]. Although ABs on chrysotile have been reported in some specific occupations [21], the biopersistance of chrysotile fibres in the lungs is much shorter than that of amphibole fibres [22] and the relevance of mineralogical analyses in assessing past exposures to chrysotile is questionable [16, 23]. According to the present authors' experience with repeated BALFs in several cases exposed to chrysotile, the biopersistence of ABs on chrysotile in BALF appears to be $<10$ yrs (unpublished results). However, observations on ABs, mainly built on amphibole fibres, appear relevant since a recent meta-analysis of mesothelioma and lung cancer mortality reports exposure-specific risks for amosite and crocidolite one-to-two orders of magnitude higher than for chrysotile [24].

The decline of asbestos use and the introduction of increasingly stringent regulations had only a very limited impact on the ABs concentrations in BALF between 1983-2000. The decrease observed over the years appears to be mainly due to the disappearance of cases with a very high AB count. Consistently, this trend would be more apparent if a series of 104 cases examined in 1980-1981, which were included in an earlier study, were taken into account [25]. These were not included in this study, as there is a high likelihood of a selection bias during this initial period, with focus on prevalent cases of primary asbestos workers with asbestosis. These cases are nevertheless interesting in confirming the observed trends. The highest AB concentrations in BALF ever measured in the laboratory were observed among these patients. Three cases had counts $>5,000 \mathrm{AB} \cdot \mathrm{mL}^{-1}$ during this period, while none have been recorded since 1983 .

The constancy in the proportion of cases with $>1 \mathrm{AB} \cdot \mathrm{mL}^{-1}$ between 1983-2000 indicates that such cases will still be detected in the future. Interestingly, there were fewer cases among those aged $<50$ yrs examined after 1991 and among those presumed to have entered working life after 1978. This is an indication that subjects from the youngest and most recently exposed group were exposed to lower cumulative doses or to less biopersistent chrysotile fibres.

Analysis of the AB's core fibre type by electron microscopy in the nine cases who entered working life after 1978 and had $>10 \mathrm{AB} \cdot \mathrm{mL}^{-1}$ also provide information on the recent exposure characteristics. First, the disclosure of $\mathrm{ABs}$ on chrysotile or pseudo-ABs on ceramic fibres in five of these cases reflects recent exposure to less biopersistent fibres that did not have sufficient time to be cleared and the use of asbestos substitutes in some applications, respectively. Secondly, one of the cases with ABs on amphiboles had been environmentally exposed in the 1960's by playing on the dumps of an asbestos cement factory as a child. Thirdly, 
the three remaining cases (one welder, one heating mechanic and one sand blaster of metallic parts) indicate that uncontrolled exposure conditions may still have occurred after 1978 .

Concerning the occupations of the subgroup with high $\mathrm{AB}$ burdens in BALF, there was a shift from "primary asbestos workers" to those exposed during handling of ACMs or to asbestos in place in buildings or industrial sites. Most of the recent cases with high $\mathrm{AB}$ counts had been exposed in construction and building-related activities, metal production and welding, or in power plants. Control of such exposures has certainly been more limited and much less efficient compared to the situation in the ACM production industry. These occupational groups account for an important fraction of the current mesothelioma cases [1, 26, 27]. Mineralogical analysis of lung tissue showed that amosite and crocidolite fibres could account for $80-90 \%$ of the mesothelioma cases in those aged $<50$ yrs old in such occupations [16].

The observations reported here support the epidemiological inferences concerning the evolution of the spectrum of asbestos-related diseases in Western countries. As a result of the implementation of exposure-control measures in the 1970 's, asbestosis is currently considered a disappearing disease, especially in its severe forms [28]. It has been estimated that clinical or radiological asbestosis is caused by cumulated exposures of $\geqslant 25$ fibres $\cdot \mathrm{mL}^{-1} \cdot \mathrm{yr}^{-1}[29,30]$. This dose is estimated to be roughly equivalent to $5-15 \mathrm{AB} \cdot \mathrm{mL}$ $\mathrm{BALF}^{-1}$ [31]. In this series [8], 90\% of asbestosis cases had $\geqslant 5 \mathrm{AB} \cdot \mathrm{mL}^{-1}$ and $75 \%$ had $\geqslant 30 \mathrm{AB} \cdot \mathrm{mL}^{-1}$. In contrast, $66 \%$ of cases with pleural plaques and $70 \%$ of mesothelioma cases had $<30 \mathrm{AB} \cdot \mathrm{mL} \mathrm{BALF}^{-1}$. The lack of a clear decreasing trend in the proportion of $\mathrm{BALF}$ with $\mathrm{AB}$ counts in this range between 1983-2000 indirectly confirms the epidemiological expectations that the incidence of mesothelioma will remain high in the near future [32]. Although most of the individuals with ABs in BALF will not develop asbestos-related malignancies, a large number of subjects are at risk and this will probably decrease only very slowly.

\section{Conclusions}

Control measures of occupational exposure levels and of asbestos consumption in Belgium have been efficient in reducing exposures resulting in very high $\mathrm{AB}$ counts, thereby preventing cases of asbestosis. A decrease in incidence is not yet expected for mesothelioma or benign pleural diseases. Due to an increase in life expectancy, more and more of these subjects will reach latencies compatible with the development of mesothelioma.

Stricter application of the existing regulations and better information for the workers still potentially at risk of exposure to asbestos in place is needed.

\footnotetext{
Acknowledgements. The authors would like to thank J.M. Caroyer, who allowed the use of patient data from the Occupational Diseases Fund, and M. Vandecauter from the Statistical Department of the Belgian Office for Foreign Trade, who provided statistics about asbestos imports in Belgium.
}

\section{References}

1. Peto J, Hodgson JT, Matthews FE, Jones JR. Continuing increase in mesothelioma mortality in Britain. Lancet 1995; 345: 535-539.
2. Goldberg M, Banaei A, Goldberg S, Auvert B, Luce D, Gueguen A. Past occupational exposure to asbestos among men in France. Scand $J$ Work Environ Health 2000; 26: 5261 .

3. Gennaro V, Finkelstein MM, Ceppi M, et al. Mesothelioma and lung tumors attributable to asbestos among petroleum workers. Am J Ind Med 2000; 37: 275-282.

4. Hodgson MJ, Parkinson DK, Sabo S, Owens GR, Feist JH. Asbestosis among electricians. J Occup Med 1988; 30: 638640.

5. Corhay JL, Delavignette JP, Bury T, Saint-Remy P, Radermecker MF. Occult exposure to asbestos in steel workers revealed by bronchoalveolar lavage. Arch Environ Health 1990; 45: 278-282.

6. Anderson HA, Hanrahan LP, Higgins DN, Sarow PG. A radiographic survey of public school building maintenance and custodial employees. Environ Res 1992; 59: 159-166.

7. De Vuyst P, Karjalainen A, Dumortier P, et al. Guidelines for mineral fibre analyses in biological samples: report of the ERS Working Group. European Respiratory Society. Eur Respir J 1998; 11: 1416-1426.

8. De Vuyst P, Dumortier P, Moulin E, Yourassowsky N, Yernault J. Diagnostic value of asbestos bodies in bronchoalveolar lavage fluid. Am Rev Respir Dis 1987; 136: 12191224.

9. Dumortier P, Gocmen A, Laurent K, Manco A, De Vuyst P. The role of environmental and occupational exposures in Turkish immigrants with fibre-related disease. Eur Respir $J$ 2001; 17: 922-927.

10. Pairon JC, Martinon L, Iwatsubo Y, et al. Retention of asbestos bodies in the lungs of welders. Am J Ind Med 1994; 25: 793-804.

11. Pairon JC, Orlowski E, Iwatsubo Y, et al. Pleural mesothelioma and exposure to asbestos: evaluation from work histories and analysis of asbestos bodies in bronchoalveolar lavage fluid or lung tissue in 131 patients. Occup Environ Med 1994; 51: 244-249.

12. Orlowski E, Pairon JC, Ameille J, et al. Pleural plaques, asbestos exposure, and asbestos bodies in bronchoalveolar lavage fluid. Am J Ind Med 1994; 26: 349-358.

13. Tuomi T, Oksa P, Anttila S, et al. Fibres and asbestos bodies in bronchoalveolar lavage fluids of asbestos sprayers. Br J Ind Med 1992; 49: 480-485.

14. Wagner JC, Moncrieff CB, Coles R, Griffiths DM, Munday DE. Correlation between fibre content of the lungs and disease in naval dockyard workers. $\mathrm{Br} J$ Ind Med 1986; 43: 391-395.

15. Churg A, Vedal S. Fiber burden and patterns of asbestosrelated disease in workers with heavy mixed amosite and chrysotile exposure. Am J Respir Crit Care Med 1994; 150: 663-669.

16. McDonald JC, Armstrong BG, Edwards $\mathrm{CW}$, et al. Case-referent survey of young adults with mesothelioma: I. lung fibre analyses. Ann Occup Hyg 2001; 45: 513-518.

17. Van Cleemput J, De Raeve H, Verschakelen JA, Rombouts J, Lacquet LM, Nemery B. Surface of localized pleural plaques quantitated by computed tomography scanning: no relation with cumulative asbestos exposure and no effect on lung function. Am J Respir Crit Care Med 2001; 163: 705710 .

18. Churg A, Warnock ML, Green N. Analysis of the cores of ferruginous (asbestos) bodies from the general population. II. True asbestos bodies and pseudoasbestos bodies. Lab Invest 1979; 40: 31-38.

19. Morgan A, Holmes A. The enigmatic asbestos body: its formation and significance in asbestos related disease Environ Res 1985; 38: 283-292.

20. De Vuyst P, Dumortier P, Gevenois PA. Analysis of asbestos bodies in BAL from subjects with particular exposures. $\mathrm{Am}$ J Ind Med 1997; 31: 699-704.

21. Dumortier P, De Vuyst P, Strauss P, Yernault J. Asbestos bodies in bronchoalveolar lavage fluids of brake lining 
and asbestos cement workers. $B r$ J Ind Med 1990; 47: 9198.

22. Churg A. Deposition and clearance of chrysotile asbestos Ann Occup Hyg 1994; 38: 625-633, 424-425.

23. Rees D, Phillips JI, Garton E, Pooley FD. Asbestos lung fibre concentrations in South African chrysotile mine workers. Ann Occup Hyg 2001; 45: 473-477.

24. Hodgson JT, Darnton A. The quantitative risks of mesothelioma and lung cancer in relation to asbestos exposure. Ann Occup Hyg 2000; 44: 565-601.

25. De Vuyst P, Jedwab J, Dumortier P, Vandermoten G, Vande Weyer R, Yernault JC. Asbestos bodies in bronchoalveolar lavage. Am Rev Respir Dis 1982; 126: 972-976.

26. McDonald JC, Edwards CW, Gibbs AR, et al. Case-referent survey of young adults with mesothelioma: II. occupational analyses. Ann Occup Hyg 2001; 45: 519-523.

27. Neumann V, Günther S, Müller KM, Fischer M. Malignant mesothelioma - German mesothelioma register 1987-1999. Int Arch Occup Environ Health 2001; 74: 383-395.
28. Becklake MR. The epidemiology of asbestosis. In: Liddell D, Miller K, eds. Mineral Fibers and Health. Florida, CRC Press, 1991; pp. 103-119.

29. Doll R, Peto J. Effects in health of exposure to asbestos. Health and Safety Commission. London, Her Majesty's Stationery Office, 1985.

30. Ontario Royal Commission. On matters of health and safety arising from the use of asbestos in Ontario. Toronto, Ontario Ministry of the Attorney General, 1984.

31. Henderson DW, Leigh J. Asbestos and lung cancer: a selective up-date to the Helsinki Criteria for indiviual attribution. In: Tossavainen A, Lethinen S, Huuskonen M, Ratanen J, eds. New Advances in Radiology and Screening of Asbestos-Related Diseases. People and Work. Research report 36. Helsinki, Finish Institute of Occupational Health, 2000; pp. 3-18

32. Peto J, Decarli A, LaVecchia C, Levis F, Negri E. The European mesothelioma epidemic. Br J Cancer 1999; 79: 666-672. 